\title{
Estágio pedogeoquímico da cobertura superficial de área fonte de depósitos de colúvio - Superfície de cimeira de Pinhão/Guarapuava, Paraná
}

\author{
Vitor Hugo Rosa BIFFI', Julio Cesar PAISANI², Laine Milene CARAMINAN', Nelson \\ Vicente Lovatto GASPARETTO?
}

\begin{abstract}
Programa de Pós-Graduação em Geografia, Universidade Estadual de Maringá. Av. Colombo, 5.790, CEP 87020-900, Maringá, PR, Brasil (vhugorosabiffı@gmail.com, caraminanlaine@gmail.com, nvlgasparetto@gmail.com).

2 Programa de Pós-Graduação em Geografia, Universidade Estadual do Oeste do Paraná. Rua Maringá, 1.200, CEP 85605-010, Francisco Beltrão, PR, Brasil (juliopaisani@hotmail.com).
\end{abstract}

\begin{abstract}
Resumo. Os estudos relacionados às caracterizações de solos e formações superficiais frequentemente utilizam-se da abordagem pedogeoquímica para fornecer bases sobre os processos envolvidos na transformação do material parental, a relação entre as características geológicas, tipo e intensidade dos processos intempéricos. Nesse contexto, o presente trabalho apresenta os resultados da mineralogia das formações superficiais alóctone e autóctone da Superfície de Cimeira de Pinhão/Guarapuava, visando a inferência do estágio pedogeoquímico da cobertura superficial. Para tal, foi realizada a técnica de difração de Raios - X (DRX), utilizando-se do método de lâmina orientada, calcinada e glicolada para a fração argila e o método do pó para as frações areia, silte e argila. Os horizontes pedoestratigráficos analisados foram: CA (topo e base), 2CAb (topo e base), 3CAb (base), 4BCb (topo e base) e 5Bb (centro). 0 DRX foi semelhante na fração argila para todos os horizontes pedoestratigráficos analisados, compostos por caulinita, gibbsita, goethita e vermiculita, no entanto, no horizonte 3BCb não foi visualizada a presença da goethita. Para o método do pó foram constatados minerais do grupo dos filossilicatos, representados pela vermiculita e caulinita, bem como tectossilicatos, com a presença do quartzo e os óxidos, hidróxidos e oxi-hidróxidos de Fe, Al e Ti, que neste caso, referem-se aos reflexos da gibbsita, hematita, goethita, ferrihidrita, magnetita, maghemita, anatásio, rutilo e ilmenita. A constituição mineralógica dos materiais sugere a atuação dos processos de hidrólise e oxi-redução, indicando que tanto a área fonte dos depósitos de colúvio quanto do paleossolo se encontra no estágio pedogeoquímico fersialítico, o que equivale a materiais em estágio moderado de intemperismo.
\end{abstract}

Palavras-chave. Planalto das Araucárias, pedoestratigrafia, mineralogia, difração de raios- $X$, formações superficiais.

Abstract. Pedogeochemical stage of surface coverage of Source area of ColluVium DEPOSITS - PINHÃO/GUARAPUAVA SUMmIT SURFACE, PARANÁ. Researches related to the characteristics of soils and superficial formations often use pedogeochemical approach to provide bases on the processes related to the transformation of the parental material, a relation between the geological featuresand the type and intensity of the weathering processes. In this context, the present work provides the results about the mineralogy of autochthonous and allochthonous superficial formations of the Pinhão/Guarapuava Summit Surface, aiming at the inference of the pedogeochemical stage of the surface covering. For this purpose, the X-ray diffraction technique (XRD) was performed, utilizing the oriented, calcined and glycolated method for the clay fraction and the powder method for the sand, silt and clay fractions. The pedoestratigraphic horizons analyzed were: CA (top and base), 2CAb (top and base), 3CAb (base), 4BCb (top and base) and $5 \mathrm{Bb}$ (middle). The XRDs showed similar minerals in the clay fraction for all pedestrostratigraphic horizons analyzed, composed of kaolinite, gibbsite, goethite and vermiculite, however, in the $3 \mathrm{BCb}$ horizon the presence of goethite was not visualized. For the powder method, minerals from the phyllosilicate group, represented by vermiculite and kaolinite, as well as tectosilicates, with the presence of quartz and the oxides, hydroxides and oxy-hydroxides of $\mathrm{Fe}, \mathrm{Al}$ and Ti, which in this case refer to reflections of gibbsite, hematite, goethite, ferrihydrite, magnetite, maghemite, anatase, rutile and ilmenite. The mineralogical constitution of the materials suggests the performance of hydrolysis and oxy-reduction processes, indicating that both the source area of colluvium and paleosol deposits are in the fersialiticpedogeochemical stage, which is equivalent 
to materials in a moderate weathering stage.

Keywords. Araucárias Plateau, pedostratigraphy, mineralogy, X-ray diffraction, superficial formations.

\section{Introdução}

Os estudos acerca dos processos evolutivos da paisagem geomorfológica no Planalto das Araucárias vêm sendo realizado com base na descrição sistemática das formações superficiais e, até o momento, foram reconhecidos materiais tanto de origem autóctone quanto alóctone, que estão em fase com as mudanças paleoambientais mesolocais que ocorreramaolongo do Quaternário, sobretudo nos Estágios Isotópicos Marinhos (EIM) 3 a 1. As pesquisas se concentram, em sua maioria, na Superfície de Cimeira de Palmas/Caçador, em que se encontram depósitos de colúvio, colúvioalúvio e alúvio, além de paleossolos enterrados e relictuais como principais marcadores de tais mudanças (Paisani et al., 2013a, 2014, 2015, 2016, 2019; Pontelli \& Paisani, 2015; Biffi \& Paisani, 2019a).

As formações superficiais quaternárias em regiões tropicais e subtropicais úmidas podem apresentar em seu registro estratigráfico indicativos de processos de natureza tanto pedogenético quanto morfogenético e, a partir da análise dos materiais, é possível reconstruir a dinâmica da paisagem ao longo do tempo (Thomas, 1989, 2008). No caso da Superfície de Cimeira de Palmas/Caçador, a análise dos processos morfogenéticos vem sendo realizada com base nos critérios morfo-, litoe aloestratigráficos, conforme recomenda Hughes (2010), e pedoestratigráficos (Catt, 1990). No geral, são reconhecidos processos de escoamento superficial e fluxos gravitacionais como principais mecanismos da ação da erosão mecânica em ambientes de encostas e fundos de vale de baixa ordem hierárquica (Paisani et al., 2013b, 2016, 2017, 2019). Por outro lado, pouco se sabe a respeito dos processos de erosão geoquímica, sobretudo nas superfícies de cimeira desse planalto, em detrimento da remoção da cobertura superficial que ocorreram no Último Máximo Glacial (Paisani et al., 2014, 2016, 2017, 2019).

Tentativas de estabelecer a gênese das formações superficiais da área fonte dos depósitos sedimentares (colúvio, colúvioalúvio e alúvio) e perfis de intemperismo foram realizadas com base nas suas características mineralógicas e geoquímicas, em que são levantadas as características de paleoperfis de intemperismo e inferidas o grau de evolução pedogeoquímica dos materiais (Thomas, 2003). Essa abordagem foi utilizada para a compreensão do estágio evolutivo das formações superficiais da Superfície de Cimeira de Palmas/Caçador, em que foram identificados processos de alitização, sialitização e bissialitização (Paisani et al., 2013a, 2014, 2015; Guerra \& Paisani, 2014). Embora tais informações sejam relevantes para o contexto mesolocal do Planalto das Araucárias, não se sabe se os processos pedogeoquímicos observados para a superfície de Palmas/Caçador se manifestaram de maneira similar nas demais superfícies de cimeira desse Planalto.

A superfície de Cimeira de Pinhão/ Guarapuava está localizada na região centro-sul do estado do Paraná, e mostra-se com moderado grau de dissecação pelos tributários da margem direita do médio vale do rio Iguaçu (Biffı \& Paisani, 2018). Nesse local, são encontradas formações superficiais alóctones e autóctones, com destaque para a ocorrência de crostas ferruginosas que remetem aos processos de ferruginização, que ocorreram entre o Plioceno e Pleistoceno Superior (Riffel etal., 2016). Depósitos de colúvio e colúvio-alúvio são encontrados em paleocabeceira de drenagem, mas pouco se sabe sobre o estágio de evolução das formações superficiais fonte desses sedimentos. Como a assembleia mineralógica apresenta uma íntima relação com os processos pedogenéticos, a "memória do solo" (Targulian \& Goryachkin, 2004) é preservada no registro dos materiais e, assim, entende-se que ela represente o último estágio pedogenético dos materiais da área fonte dos colúvios. Nesse sentido, o presente trabalho apresenta os resultados da mineralogia das formações superficiais autóctones e alóctones de uma paleocacebeira de drenagem na Superfície de Cimeira de Pinhão/Guarapuava. 


\section{2 Área, materiais e métodos}

\subsection{Localização da área}

O Planalto das Araucárias é uma unidade geomorfológica que ocupa cerca de $3 / 4$ da região sul do Brasil e exibe diferentes níveis altimétricos que localmente foram identificados como remanescentes de superfícies incompletamente aplainadas (Paisani et al., 2008; Paisani et al., 2013a). Na borda leste desse planalto, ocorrem as superfícies de Cimeira com altitudes médias de 1.200 m (Fig.1) (Almeida, 1956; Biffi \& Paisani, 2018). A superfície é mantida por rochas de natureza ácida (predominantes) intermediária e básica de idade Neocretácea, que constituem o Grupo Serra Geral (Fodor et al., 1989; Nardy et al., 2002; Schenato et al., 2003; Mineropar, 2013).

$\mathrm{Na}$ superfície de Pinhão/Guarapuava, aflora riodacitos da Formação Covó - Membro Guarapuava (Fig. 2A). Os riodacitos são cinzaesverdeados, porfiríticos com matriz fanerítica fina e hipohialina. A estrutura varia de maciça e isótropa a bandada, geralmente pouco vesicular, com vesículas irregulares de 1-2 mm de diâmetro preenchidas por clorita, que representam 3-5\% do volume da rocha. 0 plagioclásio é subédrico, com 5-15 mm de aresta e constitui 50\% dos fenocristais; feldspato potássico é subédrico e representa 20\%; piroxênio e quartzo são anédricos, com 3-5 mm de diâmetro e somam $10 \%$ dos fenocristais, em matriz parcialmente desvitrificada com micrólitos de feldspato potássico e plagioclásio. Piroxênio e magnetita de 1-2 mm de diâmetro representam 5\% cada. Em poucos afloramentos, o riodacito é intensamente vesicular, com vesículas de 5 por $15-20 \mathrm{~mm}$, e localmente brechado, com fragmentos subarredondados de andesito (Mineropar, 2013).

O relevo é caracterizado como suavemente ondulado a moderadamente ondulado, com morfologia de topos aplainados e vertentes retilíneas e/ou convexas, e depressões fechadas (Santos et al., 2006). A superfície manifesta aspectos meteorológicos locais que a caracteriza como clima temperado úmido (Cfb na classificação de Köppen), com temperaturas que variam entre 16 e $20^{\circ} \mathrm{C}$ e precipitação média anual registrada na estação climatológica de
Guarapuava de 1.900 mm.ano-1 (Biffi, 2019). A cobertura vegetal natural predominante da superfície é Estepe Gramíneo-Lenhosa (Campos), com Floresta Ombrófila Mista (Floresta de Araucária) nas maiores altitudes e nos fundos de vales (Biffi, 2019).

\subsection{Materiais e métodos}

A análise das formações superficiais foi deduzida com base na caracterização mineralógica dos materiais que constituem a seção estratigráfica RI-1. A área se mostrou com potencial em função da evidência macroscópica de materiais com diferentes características físicas (alóctones e autóctones). A seção estratigráfica foi identificada em prospecção de campo em corte de estrada, e caracterizada com base na conjugação dos critérios lito-, crono-, pedo-, e aloestratigráficos (Catt, 1990; Hughes, 2010), cujas unidades estão sintetizadas na figura 2B.

Para a análise mineralógica, foi realizada a técnica de difração de Raios- X (DRX), utilizandose do método do pó nas frações areia, silte e argila, e pelo método de lâmina orientada, calcinada e glicolada para a fração argila. As amostras foram coletadas a partir do afloramento exposto no corte de estrada, com exceção da amostra 5Bb, que teve a coleta realizada com o auxílio de trado holandês. A escolha dos locais de amostragem foi determinada com base nos limites de cada nível pedoestratigráfico (topo e/ou base). A análise foi realizada em oito amostras, e corresponde aos horizontes CA (topo e base), 2CAb (topo e base), 3CAb (base), 4BCb (topo e base) e 5Bb (topo).

A preparação das amostras para a análise mineralógica seguiu os procedimentos apresentados por Albers et al. (2002) e Resende et al.(2005) e foi realizada no laboratório de sedimentologia do Grupo de Estudos Multidisciplinares do Ambiente GEMA, da Universidade Estadual de Maringá. O ensaio de difração de todas as amostras em lâmina orientada ou na forma de pó foi obtido no equipamento Shimadzu XRD-6000, do Complexo de Centrais Analíticas - COMCAP, utilizando radiação CoKa e monocromador de carbono, operado a $30 \mathrm{~mA}$ e $40 \mathrm{kV}$, com varredura de $0,02^{\circ} 2 \theta$ 


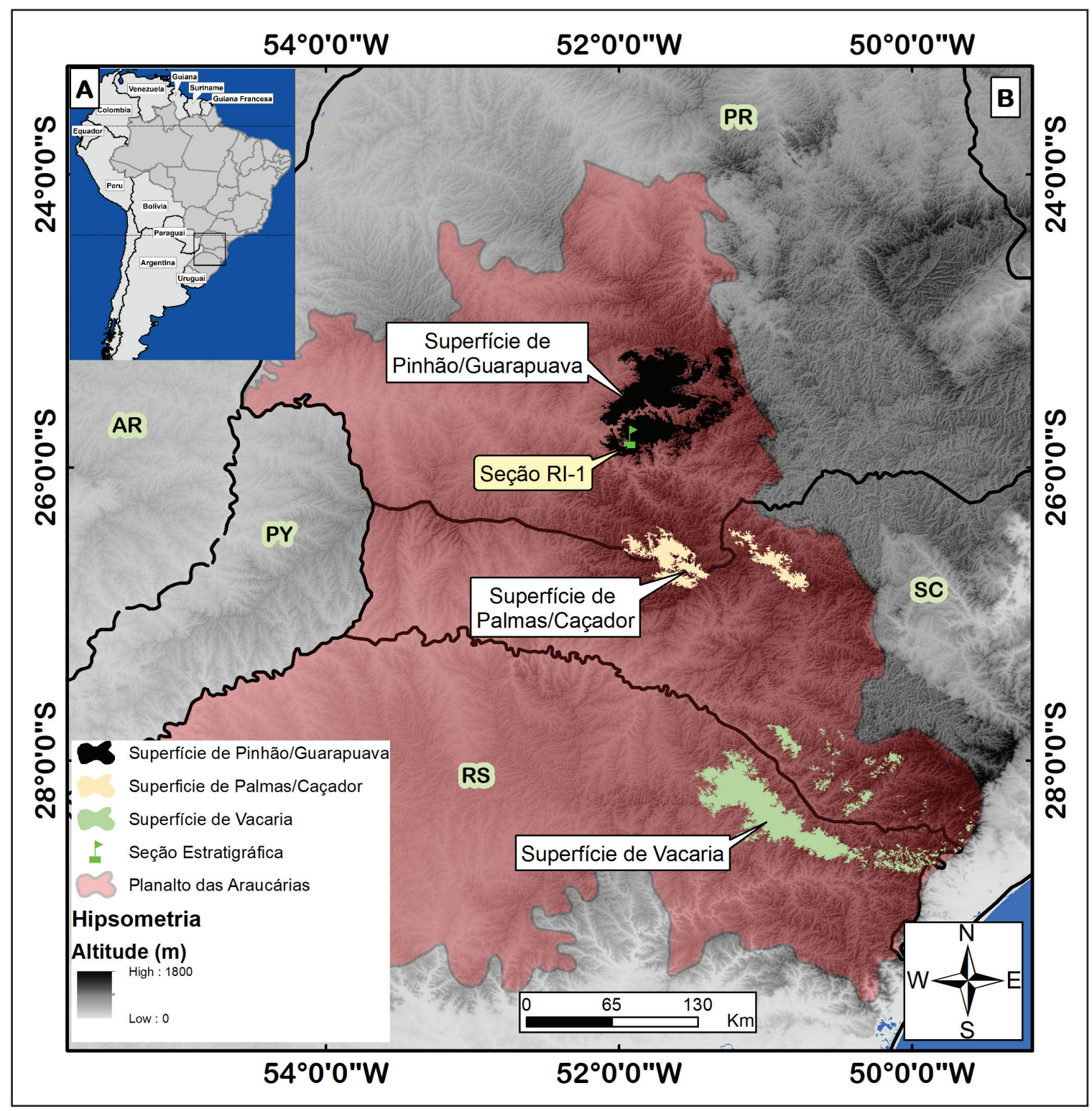

Figura 1. Localização das superfícies de cimeira do Planalto das Araucárias no Sul do Brasil (A), com destaque para a superfície de Pinhão/Guarapuava e a seção estratigráfica RI-1 (B). PR: Paraná, AR: Argentina, PY: Paraguai, SC: Santa Catarina, RS: Rio Grande do Sul.

Figure 1. Location of the summit surfaces of the Araucarias Plateau in southern Brazil (A), with emphasis on the Pinhão/ Guarapuava surface andstratigraphic section RI-1(B).PR: Paraná, AR: Argetina, PY: Paraguay, SC: Santa Catarina, RS: Rio Grande do Sul.

por 1,2 segundos. Os dados brutos obtidos pelo ensaio de difração de raios-x e foram importados para o software HighScore Plus, e compilados os tratamentos (pó, natural, glicolada e calcinada, respectivamente) e elaborado os difratogramas. Para a identificação dos constituintes minerais, determinou-se o espaçamento interplanar dos reflexos de minerais pela Lei de Bragg, assinalados conforme os reflexos apresentados por Resende et al. (2005) e Moore \& Reynolds Jr. (1997).

As amostras foram destorroadas em almofariz de ágata, previamente esterilizados com propanona $\left(\mathrm{C}_{3} \mathrm{H}_{6} \mathrm{O}\right)$, até granulometria inferior a peneiramalha de $74 \mathrm{~mm}$. Foram separadas duas amostras, uma alíquota de $1,5 \mathrm{ml}$ para ensaio de difração pelo método do pó, e outra alíquota de 20,0 mg para o método de lâmina orientada. Para o método de lâmina orientada, inicialmente foi separada a fração argila, seguida da elaboração de uma solução argila-água com concentração de 60,0 mg de argila por $1 \mathrm{~cm}^{3}$ de água destilada. A solução foi retirada com pipeta $3,0 \mathrm{ml}$ e depositada em lâmina de vidro, compatível com porta amostra utilizada no difratômetro. Posteriormente, as lâminas foram secas em estufa a $60^{\circ} \mathrm{C}$ antes da realização do ensaio de difração. 
As amostras em duplicatas foram submetidas a dois tratamentos, sendo que o primeiro constitui o aquecimento a $550{ }^{\circ} \mathrm{C}$ via mufla, para calcinação, e posteriormente, o ensaio de difração. No segundo tratamento, as lâminas orientadas foram designadas ao ensaio de difração (natural) e em seguida, submetidas à solvatação via etilenoglicol. Para a glicolagem, foi adicionado $100 \mathrm{ml}$ de etilenoglicol em recipiente, submetendo as lâminas em suporte de modo que lâminas não entrassem em contato direto com o reagente. 0 recipiente foi tampado por 5 horas e submetidos à estufa a $90^{\circ} \mathrm{C}$, e depois realizado o ensaio de difração.

\section{Resultados}

\subsection{Descrição pedoestratigráfica dos materiais}

A seção descrita apresenta cerca de $70 \mathrm{~m}$ de comprimento e 6,30 m de altura e se encontra em ambiente de encosta inserida em paleocabeceira de drenagem fossilizada (Fig. 2C). A arquitetura deposicional evidencia a presença de colúvios na porção côncava da encosta e afloramento da alterita na porção convexa do topo. Ao longo da seção, se destaca o nível estratigráfico enterrado decorbruno-muito-escuro,o qual correspondente aopaleossolo acumulativo (Biffi etal., 2019b). o paleossolo é descontínuo lateralmente e parcialmente truncado por incisão erosiva linear (Fig. 2D). A incisão tem 10,50 m de largura e 2,40 $\mathrm{m}$ de profundidade e corresponde à voçoroca colmatada por sedimentos colúvio-aluviais (Biffı et al., 2019b). Além da sequência colúvio-aluvial (CAp e CA) e o paleossolo acumulativo (2CAb), duas sequências coluviais (horizontes $3 C A b$, $3 \mathrm{BCb}$ e 4BCb) foram reconhecidas em campo, além de um nível de paleossolo (5Bb, 5BCb e 5Cgb) enterrado in situ (Biffi, 2019).

Devido à recorrente incidência da pedogênese nos materiais, os registros receberam nomenclatura pedoestratigráfica, similarmente ao estabelecido para outras seções estratigráficas da superfície de Palmas/Caçador (Paisani et al., 2019). Os materiais da sequência colúvio-aluvial que colmataram a paleovoçoroca foram individualizados em dois horizontes. O primeiro corresponde ao horizonte superficial
CAp, e apresentam cor 5YR 3/4 no topo, variando para 10YR 5/6 em direção a base. A textura varia de francossiltosa a argilossiltosa e a estrutura é pequena, moderada a fraca, em blocos subangulares a prismáticos. Datação obtida via LOE indica cronologia de 1.080 \pm 140 anos AP (Biffi, 2019).

O segundo volume (horizonte CA) apresenta transição gradual em relação ao nível sobrejacente e sutil melanização por matéria orgânica, bem como presença de pedoporos. Possui espessura média de $95 \mathrm{~cm}$ e exibe cor 5YR 4/6 a 10YR 4/4. A estrutura é forte, pequena e em blocos subangulares. A consistência é dura quando seca e friável quando úmida. Nesse horizonte, é comum a presença de fragmentos siliciclásticos (Biffi, 2019).

O nível do Paleossolo acumulativo se trata de material de difícil subdivisão interna em decorrência da alta variabilidade das frações granulométricas. Dessa forma, foi classificado como apenas um nível pedoestratigráfico (2CAb). Possui espessura média de $90 \mathrm{~cm}$, cor 7,5 YR 2,5/3 a 10 YR 2/2 com transição abrupta para o horizonte subjacente. A estrutura predominante é moderada a forte, pequena, e em blocos lamelares a subangulares, consistência macia quando seca e friável quando úmida. A textura variou entre francoargilossiltosaafrancoarenosa. Datação obtida via LOE para o topo desse nível indica cronologia de 5.350 \pm 1.040 anos A.P. e $18.300 \pm 2.300$ anos AP para a base (Biffi, 2019).

A sequência coluvial intermediária foi diferenciada em dois horizontes pedoestratigráficos. 0 primeiro corresponde ao horizonte 3CAb, com $40 \mathrm{~cm}$ de espessura média e cor 2,5 YR 3/6. A estrutura é pequena, forte, em blocos subangulares a prismática, consistência macia quando seca e friável quando úmida. Nesse horizonte, destaca-se a recorrência de pedotubulos preenchidos por material vermelho-brunado. Datação obtida da matéria orgânica sugere idades de 19.793 anos cal A.P. O segundo horizonte corresponde ao 3BCb, e possui espessura média de $50 \mathrm{~cm}$ e cor $5 \mathrm{YR}$ 2.5/2. A estrutura predominante foi moderada a forte, pequena, e em blocos lamelares a subangulares, consistência macia quando seca e friável quando úmida. A textura é variável, de 


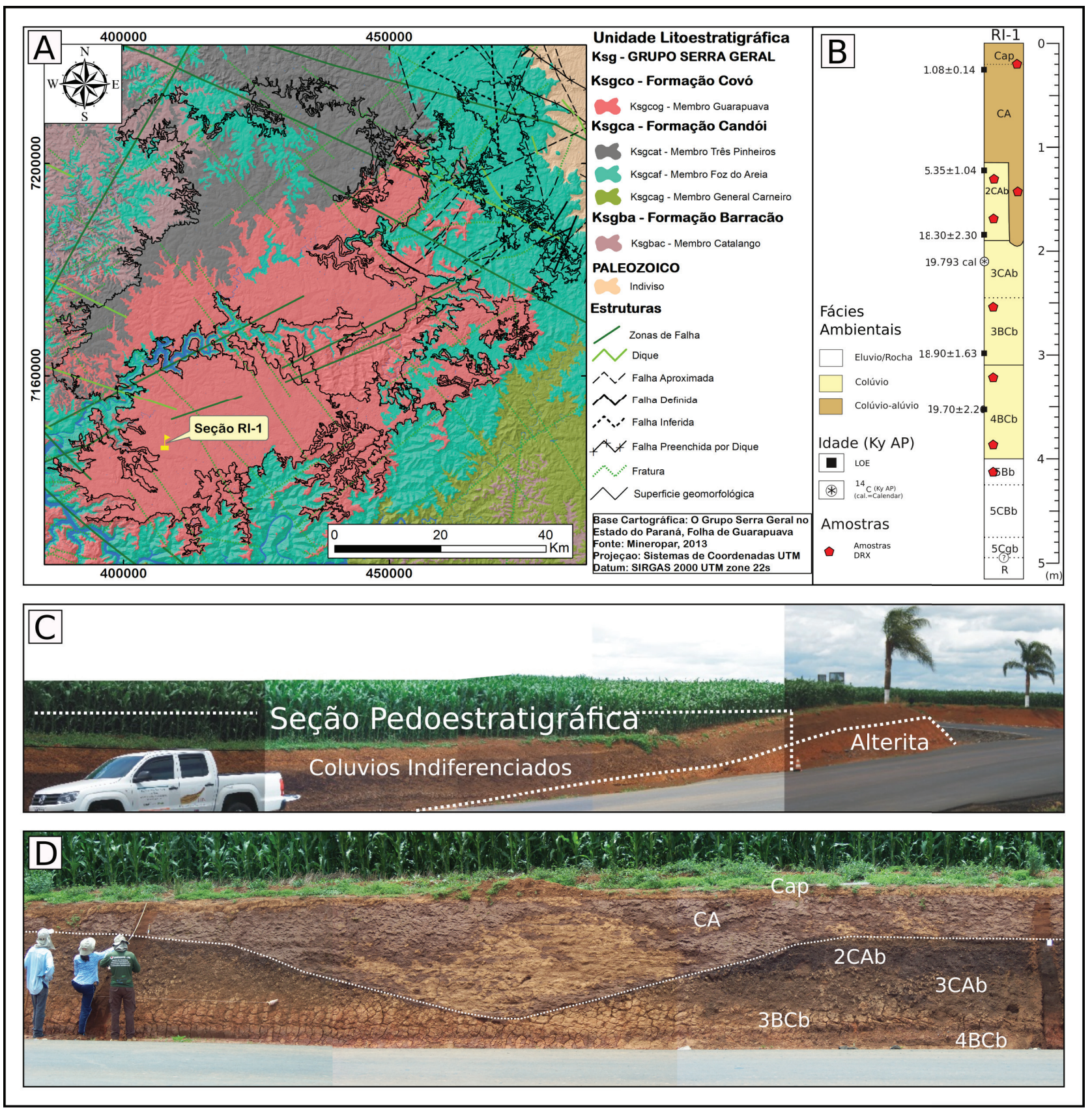

Figura 2. Localização da Seção estratigráfica RI-1 no contexto geológico da Superfície de Cimeira de Pinhão/Guarapuava (A). Seção colunar síntese do registro estratigráfico da seção (B). Imagens da seção estratigráfica, indicando os principais níveis descritos (C e D).

Figure 2. Location of the stratigraphic section RI-1 in the geological context of the Pinhão/Guarapuava Summit Surface (A). Columnar section summarizing the stratigraphic record described (B). Images of the stratigraphic section, indicating the main levels described ( $C$ and $D)$.

franco-argiloarenosa a argilossiltosa.

A sequência coluvial basal corresponde ao horizonte (4BCb) e possui $105 \mathrm{~cm}$ de espessura média, cor 2,5 YR 3/6 a 5YR4/6. Apresenta textura argilosa, estrutura moderada a forte, pequena, em blocos prismáticos, consistência macia quando seca, e friável quando úmida. Datação via LOE indica a cronologia de $19.700 \pm 2.260$ anos A.P (Biffi, 2019). Abaixo do horizonte 4BCb, os materiais correspondentes ao paleossolo in situ, em que foram diferenciados em três horizontes pedoestratigráficos $(5 \mathrm{Bb}, 5 \mathrm{CBb}$ e $5 \mathrm{Cgb})$. O primeiro possui espessura média de $25 \mathrm{~cm}$, cor $5 Y R$ 4/6, consistência macia quando seca e friável quando úmida. 0 horizonte $5 \mathrm{CBb}$ apresenta em média $70 \mathrm{~cm}$ de espessura, cor variante de 5YR 4/6 a 7,5 YR 5/6, consistência dura quando seca e firme quando úmida. Por fim, o horizonte $5 \mathrm{Cgb}$ possui espessura média de 30 cm, cores 5YR 5/6, a 2.5YR 6/8, consistência dura 
quando seca, e firme quando úmida. Em geral, tais horizontes apresentam textura argilossiltosa a argilosa (Biffi, 2019).

\subsection{Mineralogia da fração argila}

De maneira geral, a partir da interpretação conjunta dos difratogramas da fração argila pelos tratamentos natural, glicolada e aquecida, foram identificados minerais semelhantes para todos os níveis pedoestratigráficos analisados, embora se notem pequenas diferenças na intensidade de determinados picos entre os níveis (Fig. 3, quadro 1).

O horizonte pedoestratigráfico CA (topo e base) exibe reflexos médios para ângulos próximos a $7^{\circ} 2 \theta \mathrm{com}$ interplanar de $14.7 \AA$ (topo) e $14.5 \AA$ Á (base) nos tratamentos orientada e glicolada, desaparecendo quando aquecido a $550{ }^{\circ} \mathrm{C}$. Diversos minerais primários ou secundários são diferenciados com esse padrão de difração, incluindo a vermiculita, esmectita, clorita e filossilicatos interestratificados (Douglas, 1989; Moore \& Reynolds Jr., 1997). Da mesma forma, argilominerais 2:1 com hidróxi entre camadas (VHE e/ou EHE), clorita aluminosa e interestratificados como clorita-vermiculita e clorita-esmectita também apresentam picos nesse mesmo intervalo, embora tenha sido descartada a possibilidade da ocorrência desses materiais, devido à capacidade de permanência após aquecimento a $550{ }^{\circ} \mathrm{C}$ (Barnhisel \& Bertsch, 1989; Moore \& Reynolds Jr., 1997). A clorita com substituição isomórfica de $\mathrm{Al}^{3+}$ por $\mathrm{Si}^{4+}$ e/ ou $\mathrm{Fe}^{2+}$ por $\mathrm{Mg}^{2+}$ ou $\mathrm{Al}^{3+}$, quando aquecida em temperaturas superiores a $500{ }^{\circ} \mathrm{C}$, apresenta incremento de duas a três vezes na intensidade dos picos (Barnhisel \& Bertsch, 1989), sendo igualmente descartada, pelo fato de não ter reagido a tal tratamento.

A definição precisa da vermiculita requer a retenção do pico em d=001 de 14.5 Á após a solvatação de glicerol, enquanto a esmectita produz um pico de primeira ordem em torno de 17.7 Á. Quando submetida à solvatação via etilenoglicol, a esmectica, que apresenta distância interplanar próximo a 15 Á, apresenta expansão com alto reflexo a 16.9 Á, processo que não ocorre com a vermiculita (Moore \& Reynolds
Jr., 1997). Portanto, nesse caso, como não houve deslocamento quando submetido a tratamento via etilenoglicol, interpretou-se o pico como vermiculita.

Ainda no horizonte CA, tanto no topo quanto na base, verificaram-se reflexos próximos a $14^{\circ} 2 \theta$ com distância interplanar média de 7.2 Á. Assim como no caso anterior, esse pico pode ser decorrente de diferentes minerais, sendo os mais comuns a clorita e caulinita. Todavia, nesse caso, apenas o tratamento com aquecimento é suficiente para diferenciar esses dois materiais. A caulinita, quando aquecida a temperaturas acima de $550{ }^{\circ} \mathrm{C}$, torna-se amorfa, perdendo seu padrão de difração e, por conseguinte, desaparece no difratograma (Moore \& Reynolds Jr., 1997), enquanto a clorita mantém o pico. Portanto, os difratogramas referentes às amostras calcinadas, os quais os picos em $14^{\circ}$ $2 \theta$ desaparecem, comprovam a ocorrência de caulinita.

Demais materiais são encontrados com diferentes padrões de difração no horizonte CA. A gibbsita foi verificada com pico em $21^{\circ} 2 \theta$, distância interplanar de $4.8 \AA$ Á (002) e em 23 20, com distância interplanar de 4.38 Á (110). 0 pico secundário da caulinita (002) foi verificado em ambas as amostras do nível CA, com reflexo em $28^{\circ} 2 \theta$, com distância interplanar de 3.58 Á, enquanto a goethita (110) foi identificada em $24^{\circ} 2 \theta$, com distância interplanar de 4.18 Á. De modo geral, todos os reflexos supracitados não sofreram descolamento quando submetidos à solvatação com etilenoglicol, descartando a possibilidade de ocorrência de minerais expansíveis aos intervalos referidos.

O horizonte pedoestratigráfico 2CAb apresenta assembleia mineralógica semelhante ao nível CA. A vermiculita exibe reflexo médio em $7.1^{\circ} 2 \theta$, com distância interplanar de 14.3 Á, enquanto a caulinita aparece em $14.2^{\circ} 2 \theta$ e $28.9^{\circ} 2 \theta$, com distância interplanar de 7.2 Á e $3.5 \AA$ Á, respectivamente. Igualmente, a gibbsita apresenta reflexos em $21.2^{\circ} 2 \theta$ e $23.5^{\circ} 2 \theta$, com distância interplanar de $4.8 \AA$ e $4.3 \AA$ Á, respectivamente, enquanto goethita aparece em $24.7^{\circ} 2 \theta$, com distância interplanar de 4.18 Á. Ainda, nota-se uma diminuição na intensidade dos picos referentes à gibbsita quando 


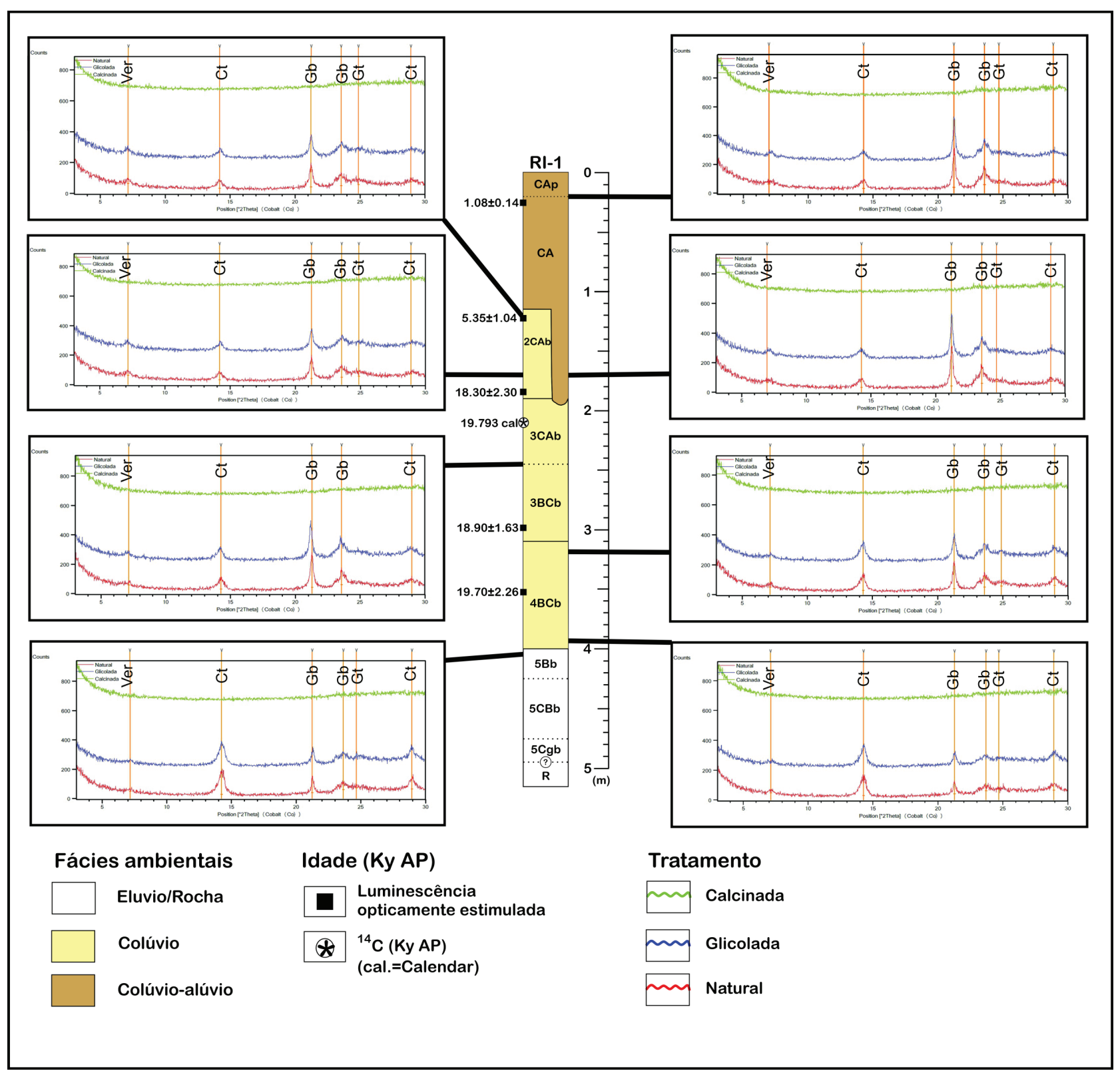

Figura 3. Difratogramas de DRX da fração argila com os tratamentos natural, glicol e aquecida a $550{ }^{\circ} \mathrm{C}$, em seus respectivos horizontes pedoestratigráficos.

Figure 3. XRD diffractograms of clay fraction with natural, glycol and heated to $550^{\circ} \mathrm{C}$ treatments, in their pedostratigraphic horizontal.

comparado à base do horizonte CA (Quadro 1).

0 horizonte pedoestratigráfico 3BCb apresenta assembleia distinta se comparado aos níveis anteriormente descritos, pois não apresentou reflexos de goethita. A vermiculita, com reflexo em $7^{\circ} 2 \theta$ de 14.6 Á apresenta redução na intensidade, enquanto a gibbsita e caulinita apresentam maiores intensidades quando comparado aos horizontes sobrejacentes. Da mesma forma, no horizonte pedoestratigráfico $4 \mathrm{BCb}$ a vermiculita com reflexo em $7^{\circ} 2 \theta$ de 14.4Á (topo) e 14.3Á (base), apresenta menor intensidade quando comparado aos horizontes
CA, 2CAb e 3C, e em contrapartida, o reflexo da caulinita (001) em $14^{\circ} 2 \theta$ apresenta maior intensidade tanto no topo quanto na base nesse horizonte. A gibbsita (002) apresenta altos reflexos em $21^{\circ} 2 \theta$ principalmente no topo, embora com menor intensidade se comparado ao horizonte $3 \mathrm{CBb}$. A goethita volta a exibir reflexos em $24^{\circ} 2 \theta$, com distância interplanar de $4.18 \AA ̊$ (Quadro 1, fig.2).

No horizonte pedoestratigráfico $5 \mathrm{Bb}, \mathrm{a}$ vermiculita apresenta a menor intensidade quando comparado aos níveis estratigráficos sobrejacentes, enquanto a caulinita possui 
Quadro 1. Argilominerais identificados nos níveis pedoestratigráficos, com seus respectivos padrões de difração d(Á), ângulo ${ }^{\circ}$ 2theta e Intensidade. Ver: Vermiculita; Ct: Caulinita; Gb: Gibbsita, Gt: Goethita.

Chart 1. Clay minerals identified at pedostratigraphic levels, with their respective diffraction patterns $d(A ́)$, angle ${ }^{\circ} 2$ theta and Intensity. Ver: Vermiculite; Ct: Kaolinite; Gb: Gibbsite, Gt: Goethite.

\begin{tabular}{|c|c|c|c|c|c|c|c|c|c|c|c|c|c|c|c|c|c|c|}
\hline \multirow[b]{2}{*}{$\begin{array}{l}\text { hor/ } \\
\text { min }\end{array}$} & \multicolumn{3}{|c|}{ Ver } & \multicolumn{3}{|c|}{ Ct (001) } & \multicolumn{3}{|c|}{ Ct (002) } & \multicolumn{3}{|c|}{ Gb (002) } & \multicolumn{3}{|c|}{ Gb (110) } & \multicolumn{3}{|c|}{ Gt (110) } \\
\hline & $\begin{array}{c}\mathrm{D} \\
(\AA)\end{array}$ & $2 \theta$ & I & 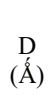 & ${ }^{\circ} 2 \theta$ & I & (Á) & ${ }^{\circ} 2 \theta$ & I & $\begin{array}{c}\mathrm{D} \\
(\hat{A})\end{array}$ & ${ }^{\circ} 2 \theta$ & I & $\begin{array}{c}\mathrm{D} \\
(\AA ̊)\end{array}$ & ${ }^{\circ} 2 \theta$ & I & $\begin{array}{c}\mathrm{D} \\
(\AA)\end{array}$ & ${ }^{\circ} 2 \theta$ & I \\
\hline $\begin{array}{c}\mathrm{CA} \\
\text { (topo) }\end{array}$ & 14,5 & 7 & 96 & 7,2 & 14 & 123 & 3,58 & 28 & 120 & 4,8 & 21 & 193 & 4,38 & 23 & 141 & 4,18 & 24 & 120 \\
\hline $\begin{array}{c}\mathrm{CA} \\
\text { (base) }\end{array}$ & 14,7 & 6,9 & 98 & 7,2 & 14 & 96 & 3,58 & 28 & 100 & 4,8 & 21 & 311 & 4,38 & 23 & 190 & 4,18 & 24 & 95 \\
\hline $\begin{array}{l}2 \mathrm{CAb} \\
\text { (topo) }\end{array}$ & 14,3 & 7 & 100 & 7,2 & 14 & 91 & 3,58 & 28 & 102 & 4,8 & 21 & 200 & 4,38 & 23 & 137 & 4,18 & 24 & 114 \\
\hline $\begin{array}{l}2 \mathrm{CAb} \\
\text { (base) }\end{array}$ & 14,3 & 7 & 100 & 7,2 & 14 & 91 & 3,58 & 28 & 102 & 4,8 & 21 & 200 & 4,38 & 23 & 137 & 4,18 & 24 & 114 \\
\hline $3 \mathrm{BCb}$ & 14,6 & 7 & 87 & 7,2 & 14 & 114 & 3,58 & 28 & 117 & 4,8 & 21 & 276 & 4,38 & 23 & 177 & - & - & - \\
\hline $\begin{array}{l}\text { 4BCb } \\
\text { (topo) }\end{array}$ & 14,4 & 7 & 83 & 7,2 & 14 & 144 & 3,58 & 28 & 122 & 4,8 & 21 & 224 & 4,38 & 23 & 149 & 4,18 & 24 & 98 \\
\hline $\begin{array}{l}4 \mathrm{BCb} \\
\text { (base) }\end{array}$ & 14,3 & 7 & 73 & 7,2 & 14 & 169 & 3,58 & 28 & 113 & 4,8 & 21 & 128 & 4,38 & 23 & 113 & 4,18 & 24 & 91 \\
\hline $5 \mathrm{Bb}$ & 14,2 & 7 & 71 & 7,2 & 14 & 202 & 3,58 & 28 & 169 & 4,8 & 21 & 147 & 4,38 & 23 & 121 & 4,18 & 24 & 104 \\
\hline
\end{tabular}

acréscimo significativo na altura dos picos em $14^{\circ} 2 \theta$ e $28^{\circ} 2 \theta$ (Tab. 1). Da mesma forma, a goethita apresenta aumento na intensidade, ao ponto que a gibbsita exibe reflexos menores quando comparada ao horizonte sobrejacente. 0 aumento na intensidade da goethita e caulinita, observado no difratograma, o diferencia dos horizontes sobrejacentes, embora possa ser explicado pela característica de horizonte B oxídico.

De maneira geral, foi possível verificar que a fração argila apresenta como componentes básicos cristalizados tanto como oxihidróxidos de ferro (goethita), quanto óxidos de alumínio (gibbsita), além de argilominerais filossilicatados 1:1 (caulinita) e 2:1 (vermiculita). Em todo caso, ambos representam como produto do intemperismo supérgeno (Moore \& Reynolds Jr., 1997).

\subsection{Mineralogia das frações areia, silte e argila}

Dentre os materiais identificados pelo método do pó, que inclui as frações areia, silte e argila, reconheceram-se minerais do tipo filossilicatos, óxidos, hidróxidos e oxi-hidróxidos de $\mathrm{Fe}$, Al e Ti como os principais produtos do intemperismo do material fonte das sequências coluviais e colúvio-aluvial. De maneira geral, a assembleia mineralógica é constituía de vermiculita $\quad\left[\mathrm{Mg}_{\mathrm{x}} / 2\left(\mathrm{Mg}, \mathrm{Fe}^{3+}\right)\left(\mathrm{Si}_{4-\mathrm{x}} \mathrm{Al}_{\mathrm{x}}\right) \mathrm{O}_{10}(\mathrm{OH})_{2}\right]$, caulinita $\quad\left[\mathrm{Al}_{2} \mathrm{Si}_{2} \mathrm{O}_{5}(\mathrm{OH})_{4}\right] ;$ gibbsita[YAl $\left.(\mathrm{OH})_{3}\right]$; quartzo $\left(\mathrm{SiO}_{2}\right)$, hematita $\left[\mathrm{aFe}_{2} \mathrm{O}_{3}\right]$, goethita $[\mathrm{aFeOOH}]$, ferrihidrita $\left[\mathrm{Fe}^{3+}{ }_{10} \mathrm{O}_{14}(\mathrm{OH})_{2}\right]$ magnetita $\left(\mathrm{\gamma}-\mathrm{Fe}_{3} \mathrm{O}_{4}\right)$, maghemita $\left[\mathrm{\gamma Fe} \mathrm{O}_{3}\right]$, anatásio $\left[\mathrm{TiO}_{3}\right]$, rutilo $\left[\mathrm{TiO}_{2}\right.$ ] e ilmenita $\left[\mathrm{FeTiO}_{3}\right]$, em todos os níveis pedoestratigráficos (Fig. 4).

Ainda com base na análise dos difratogramas, foi possível verificar a ocorrência de mais de uma fase mineral por amostra, em especial aos óxidos e oxi-hidróxidos de ferro. Tanto a caulinita quanto o quartzo também apresentaram mais de um pico, e apenas a vermiculita foi identificada em apenas uma fase. Assim como observado para a fração argila, a assembleia mineralógica representa o produto do intemperismo supérgeno, seja por meio de minerais neoformados ou como mineral resistente às condições de intemperismo impostas.

\section{Discussão dos resultados}

\subsection{Mineralogia da fração argila}

A interpretação dos difratogramas referentes à fração argila revelou a predominância de minerais secundários sobre 


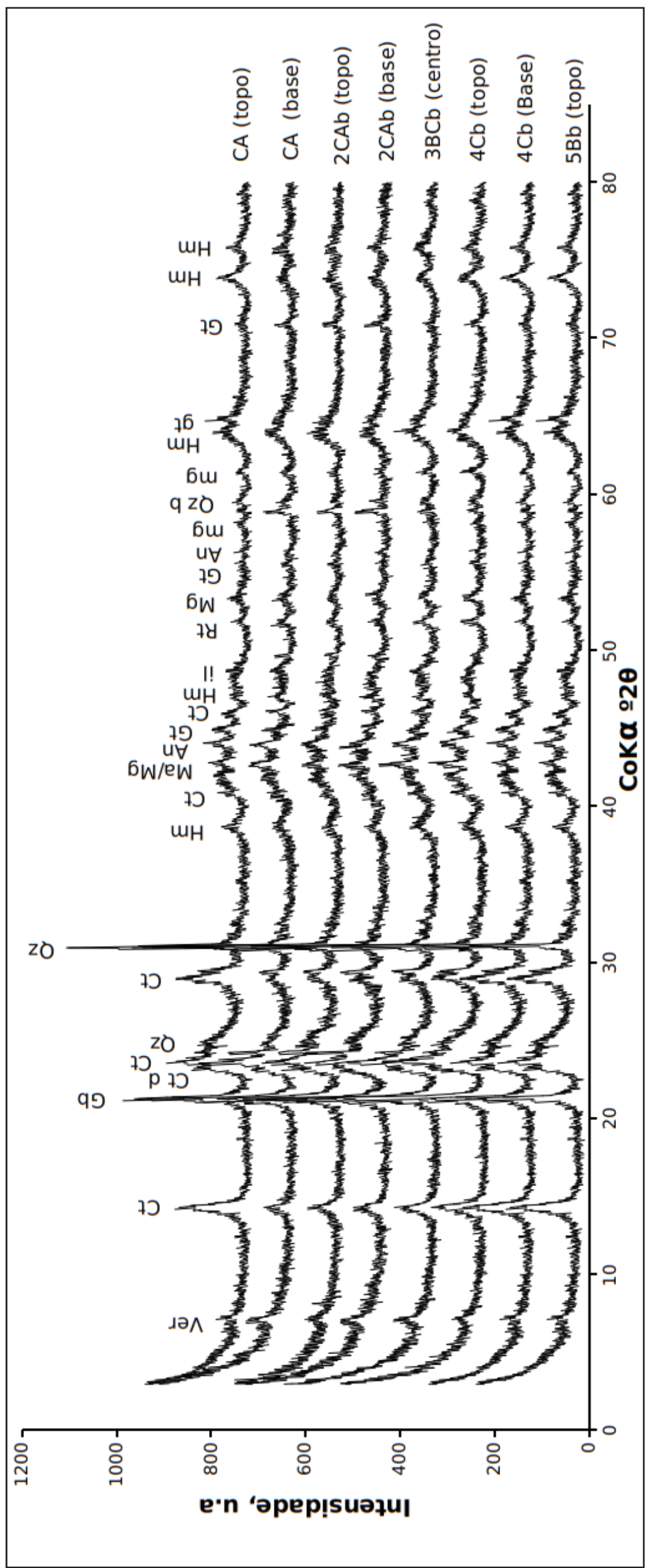

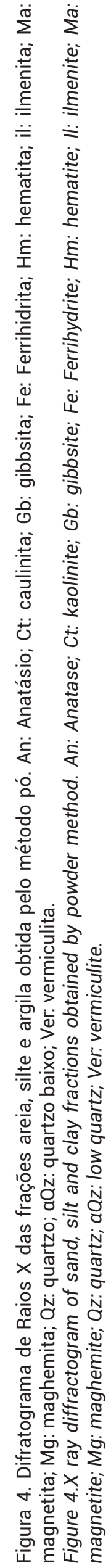


os primários. A simples análise desse fato revela que as condições de intemperismo foram intensas o suficiente para promover a completa alteração dos materiais primários nessa fração granulométrica. Além disso, foram identificados minerais 1:1, 2:1 e óxido ferro e alumínio. As condições ambientais para a ocorrência e formação de cada um dos argilominerais podem ser interpretadas como antagônicas se utilizado modelo da termodinâmica ou cinética e, portanto, inicialmente serão analisadas de forma individual, e posteriormente em conjunto.

A gênese da vermiculita foi averiguada por diversos autores, em diferentes formações superficiais, material parental e condições climáticas. No geral, as pesquisas sugerem que a origem da vermiculita pode estar relacionada tanto pela alteração de micas (muscovita ou bitotita), quanto da clorita (Barshad \& Kishk, 1969; Rebertus et al., 1986; Allen \& Hajek, 1989), ou ainda pode ser formada pela alteração de feldspatos, via precipitação de gels (Smith, 1962). Vermiculitas dioctaédricas e trioctaédricas são encontradas em diferentes condições ambientais, embora as dioctaédricas predominem em condições de intemperismo mais severo, e ocorrem preferencialmente na forma de vermiculita hidroxi-entrecamadas. As vermiculitas dioctaédricas ocorrem da alteração da muscovita, pela remoção do potássio (Malla, 2002), enquanto as vermiculitas trioctaédricas ocorrem preferencialmente em condições de intemperismo moderado, formadas tanto da ação de soluções supérgenas quanto da alteração de minerais como a biotita, flogopita ou clorita (Douglas, 1989; Malla, 2002). Sob condições de pH ácido e intemperismo intenso, as micas estão presentes na assembleia mineralógica, enquanto a vermiculita trioctaédrica também podem ocorrer com hidroxi-Al entrecamadas (Rich, 1956; Rebertus et al., 1986).

Embora a origem de filossilicatos 2:1 seja comumente associada a clima mais seco, a gênese da vermiculita foi verificada em diferentes pedoambientes de natureza hidrolítica e de oxiredução (Douglas, 1989). Em substrato vulcânico, o ferro presente na biotita se apresenta em estado divalente, enquanto o ferro que ocorre na maioria das vermiculitas trioctaedrais ocorre no estado trivalente. Durante o estágio de alteração, parte do $\mathrm{Fe}^{2+}$ é dissolvida e sofre remobilização via solução e, parte sofre oxidação e precipitação. Esse processo simultâneo de oxidação e remoção do Fe da biotita pode resultar na formação da vermiculita com hidroxi-Fe (Vicente-Hernandez et al., 1983).

Todavia, sabendo que o material parental que aflora na área apresenta clorita, geralmente preenchendo as vesículas dos riodacitos, e por não serem encontrados registros da ocorrência de minerais micáceos no substrato da Superfície de Pinhão/Guarapuava, acredita-se que a vermiculita é formada da alteração da clorita, sendo os processos de remoção do $\mathrm{Fe}^{2+}$ ou sua oxidação e remoção, juntamente a lâmina de $\mathrm{Mg}(\mathrm{OH}) 2$, uma explicação viável para a formação e ocorrência desse mineral nos materiais descritos (Adams, 1976; Kämpf et al., 2009). Dessa forma, pode-se entender que a sequência de intemperismo da clorita para vermiculita ocorre pelo seguinte processo:

Clorita $\rightarrow$ Clorita secundária $\rightarrow \mathrm{VHE} \rightarrow$ vermiculita

A transformação da clorita em vermiculita pode ocorrer já na fração argila, nos horizontes $\mathrm{B}$ e $\mathrm{C}$, e geralmente estão associados ao processo de oxidação e ação de ácidos orgânicos sob regime climático moderadamente frio e/ou bem drenados (Bain, 1977; Ross et al., 1982). Em caso de cloritas ricas em ferro, o intemperismo ocorre em três etapas:

Clorita $\rightarrow$ clorita/vermiculita $\rightarrow$ vermiculita $\mathrm{HE} \rightarrow$ Vermiculita

A continuidade desse processo leva à formação da caulinita e óxidos de ferro livre, que eventualmente substituem a vermiculita (Barnhisel \& Bertsch, 1989).

A formação e ocorrência da caulinita, do ponto de vista clássico, requer condições pedoambientais com altas relações de $\mathrm{Al} /$ $\mathrm{Si}, \mathrm{pH}$ baixo e virtual ausência de $\mathrm{Na}, \mathrm{Ca}$, Mg e $K$ na solução do solo (Melo \& Wypch, 2009). Por outro lado, em rochas vulcânicas ácidas e básicas, verifica-se a ocorrência de caulinita tanto na alterita, quanto no solum (Menegotto \& Gasparetto, 1987), o que sugere que podem ser originadas tanto nos processos 
de alteroplasmação, quanto pedoplasmação (Delvigne, 1998). Na fase de alteroplasmação, a caulinita ocorre pela alteração de feldspatos-K (Menegotto \& Gasparetto, 1987), embora quaisquer minerais que contenham Si podem ser precursores da caulinita em condições de elevado intemperismo, a partir da liberação de seus constituintes na solução do intemperismo químico. Na fase de pedoplasmação, a caulinita pode ser formada pela recristalização do Si e Al presentes na solução do solo (neogênese), ou pela transformação de outros minerais secundários ricos nesses elementos químicos (Melo \& Wypych, 2009).

$\mathrm{Na}$ região que engloba os municípios de Pinhão (PR) e Entre Rios (PR), Clemente \& Azevedo (2007) identificaram que durante o processo de intemperismo de plagioclásios, ocorre à formação de caulinita e, associada à precipitação de gels, a paragênese da gibbsita. A Análise Elemental dos cristais de plagioclásio revelou altas quantidades de Si e Al, que poderiam ser decorrentes da associação tanto de caulinita quanto de interestratificado caulinita/2:1. De fato, a partir da análise dos reflexos da caulinita, principalmente os picos com distância interplanar de 7.2 Á, verifica-se que os reflexos são largos, característica que frequentemente é relacionada a interestratificação de camadas de argilominerais 1:1 - 2:1 nos cristais de caulinitas (Azevedo \& Vidal-Torrado, 2009; Almeida et al., 2018a, 2018b), sendo o mais comum a caulinitaesmectita.

A ocorrência de interestratificado caulinitaesmectita é vista como decorrente do estágio intermediário entre a transformação da esmectita para caulinita em ambientes ricos em cátions básicos e/ou mal drenados (Vingiani et al., 2004; Ryan \& Huertas, 2009), via perda deFe da esmectita com precipitação subsequente de caulinita-Fe e minerais secundárias de Fe (Bühmann \& Grubb, 1991; Vingiani et al., 2004). Entretanto, a natureza desses argilominerais, assim como a estimativa do grau dessa interestratificação não pode ser realizada pela técnica de difração e, portanto, ainda é uma questão em aberto.

As proposições clássicas de formação da gibbsita consideram como decorrente do estágio final de alteração geoquímica, e ocorre principalmente em áreas de intemperismo intenso sob domínio da hidrólise (Melfı \& Pedro, 1977; Hsu, 1989), sendo frequentemente verificada como produto da alteração de feldspato sódico-potássico (Young \&Stephan, 1965). Em condições quentes, úmidas e com material parental vulcânico, Bates (1960) sugere que a gibbsita pode ser formada por três vias: 1) pela remoção de sílica da haloisita (filossilicato do grupo da caulinita); 2) via desidratação de gels de Al e Fe-Al e, 3) pela precipitação de soluções ricas em Al. Por vezes, tais vias podem ocorrer de maneira conjunta, embora o segundo caminho seja predominante em condições de dessecação. Por outro lado, como as condições climáticas e paleoclimáticas da área de estudo permaneceram como frias (Biffi, 2019), entendese que os processos pedogeoquímicos que predominaram ao longo do último ciclo glacial são distintos dos processos supracitados.

Em áreas vulcânicas ácidas do sul do Brasil, a formação da gibbsita foi averiguada por Clemente \& Azevedo (2007). Em síntese, os autores identificaram três caminhos para a formação da gibbsita: 1) Diretamente da alteração de plagioclásios, e 2) Alteração de plagioclásio para gels amorfos e gibbsita, e 3) plagioclásios para gel, gibbsita e caulinita. Os mesmos autores identificaram a formação de gibbsita pela alteração de piroxênios, associadas à goethita. Nos níveis pedoestratigráficos analisados, verificou-se picos com altos reflexos em $21^{\circ}$ 2theta e distância interplanar de 4.8 Á, sugerindo processo de dessilicificação intenso, tendendo para processo de alitização.

A goethita, identificada nas amostras analisadas, com exceção do horizonte 3BCb, é um mineral abundante na maioria das formações superficiais derivadas de substrato vulcânico e ocorre em quase todos os ambientes pedogênicos, fases de alteração e posição do relevo (Costa \& Bigham, 2009). Esse oxihidróxido pode ser formado pela alteração de quaisquer minerais ricos em ferro, incluindo olivinas, piroxênios, anfibólios e micas, comandados por processos de oxidação, redução, hidrólise, quelação, protólise e biomineralização. Em sistemas de solo e sedimentos, é razoável supor que as maiorias dos óxidos de Fe secundários 
se formem por oxidação e hidrólise de $\mathrm{Fe}^{2+}$ dissolvido. Em todos os casos, a taxa de oxidação é um fator importante, que depende de vários outros parâmetros, incluindo $\mathrm{pH}, \mathrm{O}_{2}$ dissolvido, atividade biológica e íons solúveis (Bigham et al., 2002). Portanto, estabelecer uma interpretação paleoambiental pode ser uma abordagem questionável.

A ocorrência concomitante de caulinita e minerais 2:1 na fração argila, embora contraditória nos modelos clássicos de evolução pedogeoquímica (Melfı \& Pedro, 1977) é previsto em ambientes imperfeitamente ou mal drenados (Ojanuga, 1979) ou em solos poligenéticos (Teske et al., 2013; Paisaniet al., 2013a; Gaspari, 2017). Em sistemas naturais, sob diferentes condições de $\mathrm{pH}$, a caulinita, gibbsita e VHE coexistem na fração argila dos solos, enquanto sob condições de pH ácido, podem ocorrer a descloritização (substituição dos polímeros) e transformação da VHE em vermiculita (Azevedo \& Vidal-Torrado, 2009). Outra possibilidade pode estar associada à reincorporação de sílica no sistema devido a mudanças ambientais, que desestabiliza alguns minerais existentes, como gibbsita, e outros são neoformados, como caulinita (Mateus et al., 2017).

\subsection{Mineralogia das frações areia e silte}

Minerais primários constituídos no material parental nas frações areia esilte, como feldspatos, plagioclásio, piroxênio e clorita não foram identificados, o que aponta que o intemperismo foi suficientemente intenso para manter apenas o quartzo, mineral mais resistente à alteração.

Embora os níveis pedoestratigráficos apresentem constituição mineralógica semelhante, foi possível verificar sutis diferenças na intensidade dos picos para determinados argilominerais entre as amostras analisadas. De maneira geral, tanto a altura quanto a largura dos picos representam o grau de cristalinidade desses minerais, sendo aqueles que com menor largura a meia altura (LMA) e maior intensidade (I) representam os minerais com maior grau de cristalização (Resende et al., 2005). Dessa forma, além da análise qualitativa da assembléia mineralógica, foi realizada a análise detalhada dos picos dos argilominerais identificados, em que foi possível verificar diferenças entre o grau de cristalização dos argilominerais nos horizontes pedoestratigráficos, e estabelecer hipóteses a respeito da área fonte dos sedimentos coluviais e colúvio-aluviais.

Com relação à vermiculita, nota-se maior grau de cristalização na base do horizonte CA e no horizonte 2CAb (Fig. 3). Em contrapartida, tanto a caulinita quanto o anatásio apresentam maior grau de cristalinidade nos horizontes CA (Topo), $4 \mathrm{BCb}$ (topoe base) e 5Bb, enquanto a gibbsita exibe maiores intensidade nos horizontes CA (Base) e 4BCb (Topo). A exceção é o horizonte 3BCb, que exibe reflexos médios tanto de vermiculita quanto da caulinita e gibbsita. Essa diferença pode expressar o grau de evolução da cobertura pedológica da área fonte dos sedimentos. Os horizontes que apresentam menores picos de vermiculita corresponderiam a horizontes menos desenvolvidos pedogeoquimicamente, enquanto aquele cuja caulinita exibe maiores picos representaria horizontes mais evoluídos.

Com relação à identificação conjunta de argilominerais 1:1 e 2:1 no mesmo contexto pedoambiental, apresentada na literatura como contraditória, algumas hipóteses podem ser levantadas a partir das formulações apresentadas por Volkmer (1999), decorrente de estudos em perfis de alteração em Pinhão, na mesma superfície geomorfológica. A partir de tal pesquisa, foram reconhecidos diferentes estágios de alteração pedogeoqúmica para um mesmo perfil de intemperismo, oriundos de processos de alteração vertical. Na fase de alteroplasmação, a partir da alteração de plagioclásios, formamse tanto a vermiculita quanto a caulinita e gibbsita, com alta acumulação relativa da última, enquanto na pedoplasmação há predomínio da caulinita e goethita, apresentando caraterísticas pedogenéticas mais evoluídas (Volkmer, 1999).

Esse fato também foi verificado por Clemente \& Azevedo (2007), para a alteração de plagioclásios, que, além de promover a formação simultânea de caulinita, gibbsita e vermiculita, seria responsável pela completa remoção dos minerais primários, à exceção do quartzo. Nesse sentido, é possível que a área fonte dos depósitos de colúvio, embora com minerais 2:1, 
apresentaria elevado estágio de intemperismo, devido a virtual ausência de minerais primários, como feldspatos, plagioclásios, piroxênios e clorita primária. As diferenças de intensidade dos picos dos minerais representariam, portanto, as diferenças de horizontes da área fonte.

Com relação aos óxidos de ferro, foram identificados hematita, goethita, ferrihidrita, magnetita e maghemita. Os óxidos de ferro se formam sob influência de diversos fatores intrínsecos à formação do solo, como temperatura, umidade, pH, Eh etc. Portanto, a ocorrência de óxidos de ferro pode refletir as condições pedoambientais as quais são formados (Kämpf \& Curi, 2000). Entretanto, uma vez formado, as fases, composições, e distribuição desses minerais estão sujeitos a constantes modificações, em busca de um novo equilíbrio com o pedoambiente (Schwertmann \& Taylor, 1989). Dessa forma, estabelecer uma interpretação paleoambiental com base nos óxidos de ferro é uma questão ambígua, podendo levar a falsas conclusões.

A goethita e a hematita, identificadas em todos os níveis pedoestratigráficos, são óxidos de ferro que se formam em condições de umidade e temperaturas antagônicas. As condições ideais para a formação da goethita envolvem baixas temperaturas e elevada precipitação, dada preferencialmente via solução, através de nucleação e crescimento de cristais cúbicos, utilizando preferencialmente os íons monovalentes de $\mathrm{Fe}^{3+}, \mathrm{Fe}(\mathrm{OH})^{2+}$ e/Ou $\mathrm{Fe}(\mathrm{OH})^{4-}$. Estes monômeros podem ser fornecidos a partir de qualquer fonte de Fe (incluindo ferrihidrita), em condições adequadas (Schwertmann \& Taylor, 1989). A hematita, por sua vez, que tem sua formação preferencialmente em zonas climáticas quentes, a partir de ferrihidrita ou seus precursores, através da agregação, desidratação e rearranjo da estrutura interna das pequenas partículas de ferrihidrita.

A associação entre hematita e goethita é relativamente comum às zonas tropicais e subtropicais. Já a ferrihidrita, que também pode ocorrer associado a outros óxidos de ferro, também é formada em diferentes contextos ambientais (Schwertmann \& Taylor, 1989). A ferrihidrita, uma vez formada, pode atuar como fonte tanto da hematita quanto da goethita e, portanto, esses dois óxidos se formam através de dois processos mutuamente competitivos.

Ao seguir o caminho de formação da ferrihidrita, verifica-se que fatores que favorecem a sua formação envolvem agregação, desidratação e rearranjo estrutural (Schwertmann \& Taylor, 1989). Na continuidade desse processo, o aquecimento da ferrihidrita, baixa quantidade de água e pH entre 6 e 8 atuam diretamente na desidratação e rearranjo da ferrihidrita para produzir hematita. Por outro lado, se os complexos Fe-orgânicos são relativamente estáveis, como nos climas frios e úmidos, o $\mathrm{Fe}^{3+}$ é liberado lentamente e a possibilidade de excreção do produto de solubilidade é reduzida, inibindo assim a formação de hematita. Assim, a formação da goethita é favorecida, pois os núcleos podem se formar a partir das espécies solúveis de $\mathrm{Fe}(\mathrm{OH})^{2+}$ liberadas (Schwertmann \& Taylor, 1989; Bigham et al., 2002; Costa \& Bigham, 2009). A transformação da ferrihidrita em goethita necessariamente passa pela sua dissolução e posterior precipitação da goethita (Costa \&Bigham, 2009). Por outro lado, se a taxa de libertação de Fe da fonte é aumentada, ou se a degradação de complexos orgânicos de Fe é acelerada, como sob condições quentes e secas, a probabilidade de exceder o produto de solubilidade da ferrihidrita aumenta.

Dentre os demais óxidos de ferro identificados, a magnetita também apresentou variações na intensidade dos picos entre os níveis pedoestratigráficos, sendo maior nos níveis CA (Topo), 4Cb (topo e base) e 5Bb. Embora esse mineral possa ser tanto litogênico quanto pedogênico, magnetita neoformada é raramente encontrada em ambientes continentais (Schwertmann \& Taylor, 1989; Costa \& Bigham, 2009). Assumido que a magnetita é primária, a variação identificada pode ser decorrente do grau de evolução da área fonte, sendo que a maior intensidade dos níveis $\mathrm{CA}, 4 \mathrm{Cb}$ e $5 \mathrm{Bb}$ representa a magnetita na forma de litorrelíquias com maior grau de cristalização. Nos demais níveis, a maior ação do intemperismo promoveu a transformação da magnetita para outros minerais ricos em ferro.

Na região de Pinhão, Volkmer 
verificou que a alteração da magnetita cristaliza inicialmente para ferrihidrita, e posteriormente para hematita ou goethita. De fato, os níveis que apresentaram maior intensidade dos picos da goethita e hematita e os picos de magnetita exibemmenor intensidade. Por outro lado, devese levar em consideração que os óxidos de ferro também podem ser originados a partir do piroxênio desde a fase de alteroplasmação, e não exclusivamente da magnetita.

A maghemita, identificada em todos os níveis estratigráficos, corresponde a um óxido de ferro secundário cuja estrutura cristalina muito se assemelha a magnetita, embora seja um polimorfo da hematita (Costa \& Bigham, 2009). Esse óxido ocorre frequentemente na fração argila, pela oxidação da magnetita via oxidação, embora também se reconheça a gênese desse material pela desidratação da lepidocrocita ou transformação de outros óxidos de ferro pedogênicos via aquecimento a temperaturas entre 300 a $425{ }^{\circ} \mathrm{C}$ associado à presença de compostos orgânicos (Schwertmann \& Taylor, 1989). Como não foi reconhecido presença de carvão ou estruturas que denotam combustão, acredita-se que esse mineral tenha se formado pela oxidação da magnetita ou ferrihidrita (Biffı, 2019). Demais óxidos, como Anatásio $\left(\mathrm{TiO}^{2}\right)$ e ilmenita $\left(\mathrm{FeTiO}^{3}\right)$ também foram identificados nos difratogramas. A ocorrência de tais óxidos é dada como materiais herdados do material fonte por serem resistentes ao intemperismo, e ocorrem preferencialmente nas frações areia e silte.

\subsection{Estágio de intemperismo da cobertura superficial e interpretações paleoambientais}

Tentativas de estabelecer o grau de evolução pedogeoquímica das formações superficiaisnas áreas planálticas do sul do Brasil vêm sendo realizado com base nas suas características mineralógicas e geoquímicas, em que as assembléias mineralógicas e índices de intemperismo de materiais alóctones e autóctones são utilizadas para inferir sobre o grau evolutivo dos materiais em uma perspectiva diacrônica (Paisani et al. 2013a, 2015; Guerra \& Paisani, 2014; Pontelli \& Paisani, 2015; Gaspari et al., 2020). Embora se reconheça as limitações dessa abordagem, a ocorrência de argilominerais filossilicatos e óxidos, hidróxidos e oxihidróxidos em materiais inconsolidados são frequentemente utilizados como indicadores de ambientes pedogênicos e geoquímicos, em que a formação e ocorrência dos minerais são associadasà contextos específicos de temperatura e umidade (Kämpf \& Curi, 2000).

No caso estudado, a assembleia mineralógica indica que o estágio de alteração da cobertura pedológica da área fonte dos depósitos de colúvio bem como o paleossolo enterrado se apresenta como fersialítica. Em regiões tropicais e subtropicais úmidas, coberturas superficiais fersialíticas representam solos em estágio de juventude, transacional para solos ferruginosos, sendo formandos em condições climáticas sazonais com estação seca bem definida (Duchaufour, 1997). De fato, a ocorrência de vermiculita, sugere que a cobertura superficial foi formada sob regime hídrico sazonal com estação seca definida, onde a perda de sílica e bases era menos acentuada, formando minerais de estrutura 2:1.

Por outro lado, em ambientes úmidos com baixas temperaturas, baixa evapotranspiração e teores elevados de matéria orgânica em meio ácido e com restrição de drenagem favorecem a formação de goethita e caulinita em detrimento da hematita e da gibbista (Ker \& Resende, 1990). Nos materiais analisados foram identificados Caulinita, Goethita, Hematita e Gibbsita, indicando ambientes pedogênicos antagônicos. Além disso, a presença de caulinita associada à ausência de minerais primários revela que o estágio de intemperismo foi suficiente para promover a alteração dos minerais mais susceptíveis às ações da intempérie, chegando ao estágio de monossialitização, enquanto a ocorrência de vermiculita sugere o processo de bissialitização. Já apresença de minerais representativos do estágio final de intemperismo, como a gibbsita, atesta hipótese da ocorrência da alitização.

Fato semelhante foi verificado por Paisani et al. (2013a) no sudoeste do Paraná e por Morrás et al. (2009) no noroeste da Argentina, e a ocorrência conjunta de tais argilominerais foram interpretadas como decorrentes das mudanças 
climáticas do Quaternário Superior. Dados paleoambientais levantados nas superfícies de cimeira do Planalto das Araucárias indicam trocas de vegetação entre campo-cerrado (savanas) e campo-limpo (estepes) para Floresta (Floresta Ombrófila Mista com Araucária), evidenciando que tais áreas responderam rapidamente as mudanças e flutuações climáticas na escala regional. Dados palinológicos e fitolíticos sugerem a ocorrência de campos até pelo menos 10.000 anos AP sob domínio de temperaturas mais frias, com períodos mais úmidos ou mais secos. Durante o Último Máximo Glacial, as áreas de campo ocuparam uma faixa de latitude de $28^{\circ} \mathrm{S}$ até $20^{\circ} \mathrm{S}$, onde as temperaturas médias anuais possivelmente eram de 5 a $7^{\circ} \mathrm{C}$ menores que às modernas (Behling 2002,2004). Já no Holoceno Inferior e Médio, os dados indicam clima frio e seco, com uma estação seca anual de cerca de três meses com o avanço das florestas apenas no último milênio (Grimm et al., 2001; Behling et al., 2004, 2009; Paisani et al., 2014, 2016, 2017, 2019; Pontelli \& Paisani, 2015; Lopes-Paisani et al., 2016; Calegari et al., 2017; Gu et al., 2017).

Dessa forma, acredita-se que durante o Último Máximo Glacial (EIM 2), sob regime climático frio e úmido, a cobertura superficial atingiu a fase de alitização e monossialitização, formando argilominerais 1:1 e óxihidródos de ferro e alumínio. Mudança para um regime mais seco no Holoceno promoveu uma alteração da monossialitização paraa bissialitização, formando minerais com estrutura 2:1, configurando do ponto de vista geoquímico, cobertura superficial poligenética.

No contexto regional, a mineralogia da fração argila em sedimentos coluviais contidos em ambiente ortomórfico na Superfície de Palmas/Caçador, mostra-se com grau de alteração elevado, indicando um processo de monossialitização e que transicionaram para bissialitização, correspondendo ao observado nesse estudo (Paisani et al., 2014, 2015; Guerra \& Paisani, 2014). De fato, as condições climáticas para a superfície de Palmas/Caçador parecem ter respondido a tais mudanças, podendo ter favorecido a formação de caulinita e gibbsita no EIM 2 pelos processos de monossialitização e alitização, de argilominerais 2:1 em detrimento da vermiculita no EIM 2, sob domínio da bissialitização (Paisani et al., 2013a; Paisani et al., 2019).

\section{Conclusões}

A caracterização mineralógica do registro estratigráfico contido em paleocabeceira de drenagem da Superfície de Cimeira de Pinhão/ Guarapuava revelou a presença de vermiculita, caulinita, gibbsita e goethita como minerais da fração argila para todos os níveis estratigráficos. Nas frações areias, silte e argila foram identificados anatásio, caulinita, gibbsita, ferrihidrita, hematita, ilmenita, magnetita, maghemita, quartzo e vermiculita, sugerindo a atuação dos processos de hidrólise e oxiredução. Isso demonstra que tanto a área fonte dos depósitos de colúvio (alta encosta) quanto o paleossolo enterrado (média encosta) apresentava solos fersialíticos, representando materiais com estágio moderado de intemperismo. Solos fersialíticos ocorrem preferencialmente em zonas subtropicais com estação seca bem definida, o que difere das condições climáticas modernas e, portanto, acredita-se que a assembleia mineralógica da fração argila remete às condições pedoambientais pretéritas.

Os resultados aqui obtidos foram comparados com aqueles já determinados para materiais em contexto estratigráfico de encosta da superfície correlata de Palmas/Caçador e correlacionado com dados paleoambientais das superfícies de cimeira do Planalto das Araucárias. Na superfície Palmas/Caçador, a mineralogia da fração argila de sedimentos coluviais em ambiente ortomórfico revelaram uma fase de alteração da monossialitização para bissialitização na passagem do Pleistoceno para o Holoceno. A partir de tais correlações, estima-se que durante o Último Máximo Glacial, sob regime climático frio e úmido, a cobertura superficial atingiu a fase de alitização e monossialitização, formando argilominerais 1:1 e óxihidródos de ferro e alumínio. Mudança para um regime mais seco no final do Pleistoceno e ao longo do Holoceno promoveu uma alteração da monossialitização para bissialitização, formando 
a vermiculita. As mudanças paleoambientais não foram suficientes para promover o retorno da hidrólise total, preservando minerais de diferentes ambientes pedogênicos e regimes climáticos como parte da memória do solo, sugerindo natureza poligenética para a área fonte dos depósitos de colúvio.

Agradecimentos. Opresentetrabalho foirealizado com apoio da Coordenação de Aperfeiçoamento de Pessoal de Nível Superior - Brasil (CAPES) Código de Financiamento 001 e do CNPq (Proc. 404592/2016-3 e 301039/2018-6)

\section{Referências}

Adams, W.A. 1976. Experimental Evidence on the Origin of Vermiculite in Soils on Lower Palaeozoic Sediments. Soil Science Society of America Journal, 40(5): 793-796.

Albers, A.P.F., Melchiades, F.G., Machado, R., Baldo, J. B. \&Boschi, A. O. 2002. Um método simples de caracterização de argilominerais por difração de raios X. Cerâmica, 48(305): 34-37.

Allen, B.L. \& Hajek, B.F. 1989.Mineral ocurrence in soil environments.In: Dixon, J.B. \& Weed, S.B. (ed.). Minerals in soil environments. Madison, Wisconsin: Soil Science Society of America, p. 199-278

Almeida, F.F.M. 1956. O Planalto Basáltico da Bacia do Paraná. Boletim Paulista de Geografia, 24: 3-34.

Almeida, J.A., Ribeiro, C.F., Oliveira, M.V.R. \& Sequinatto, L. 2018a. Mineralogia da argila e propriedades químicas de solos do Planalto Norte Catarinense. Revista de Ciências Agroveterinárias, 17(2): 267-277.

Almeida, J.A., Corrêa, J. \& Schmitt, C. 2018b. Clay Mineralogy of Basaltic Hillsides Soils in the Western State of Santa Catarina. Revista Brasileira de Ciência do Solo, 42: 1-17.

Azevedo, A.C. \& Vidal-Torrado, P. 2009. Esmectita, vermiculita, minerais com hidróxientrecamadas e clorita. In: Melo, V. F. \& Alleoni, L. R. F. (ed.). Química e mineralogia do solo: Parte I - Conceitos básicos. Viçosa, Sociedade Brasileira de Ciência do Solo, p.381-426
Bain, D.C. 1977. The weathering of chloritic minerals in some Scottish soils. Journal of Soil Science, 28(1): 144-164.

Barshad, I. \& Kishk, F.M. 1969. Chemical composition of soil vermiculite clays as related to their genesis. Contributions to Mineralogy and Petrology, 24(2): 136-155.

Barnhisel, R.I. \& Bertsch, P.M. 1989. Chlorites and Hydroxy-interlayered Vermiculite and Smectite. In: Dixon, J. B. \& Weed, S. B. (Ed.). Minerals in soil environments. Madison, Wisconsin: Soil Science Society of America, p. 729-788.

Bates, T.F. 1960. Halloysite and Gibbsite Formation in Hawaii. Clays and Clay Mineralogy, 9(1): 315-328.

Behling, H. 2002. South and southeast Brazilian Grassland during Late Quaternary times: a synthesis. Palaeogeography, Palaeoclimatology, Palaeoecology, 177: 1927.

Behling, H., Pillar, V.D., Orlóci, L. \& Bauermann, S.G. 2004. Late Quaternary Araucaria forest, grassland(Campos), fire and climate dynamics, studied by high-resolution pollen, charcoal and multivariate analysis of the Cambará do Sul core in Southern Brazil. Palaeogeography, Palaeoclimatology, Palaeoecology, 203(3-4): 277-297.

Behling, H., Jeske-Pieruschka, V., Chüler, L. \& Pillar, V.D.P. 2009. Dinâmica dos campos no sul do Brasil durante o Quaternário Tardio. In: Pillar, V.D.P., Müller, S.C., Castilhos, Z.M.S. \& Jacques, A.V.A. (Ed). Campos sulinos: conservação e uso sustentável da biodiversidade. Brasília: MMA, p. 13-25.

Biffi, V.H.R. 2019. Evolução de encosta em contexto de paleocabeceira de drenagem da Bacia do Rio Capão Grande no Quaternário Tardio - Superfície de Pinhão/Guarapuava. Francisco Beltrão, 193p. Dissertação de Mestrado, Programa de Pós-Graduação emGeografia, Universidade Estadual do Oeste do Paraná.

Biffi, V.H.R. \& Paisani, J.C. 2018. Superfícies de cimeira do Planalto das Araucárias - Sul do Brasil. Revista Brasileira de Geomorfologia, 19(3): 465-481.

Biffi, V.H.R. \& Paisani, J.C. 2019a. Micromorfologia 
de colúvio-alúvios em paleovoçorocas colmatadas nas superfícies de cimeira de Pinhão/Guarapuava e Palmas/Caçador - Sul do Brasil. Revista Brasileira de Geomorfologia, 20 (4): 735-749.

Biffi, V.H.R., Gazola, K.C. \& Paisani, J.C. 2019b. Paleossolo ou colúvio? Gênese de horizonte A acrescional em ambiente de encosta - superfície geomorfológica de Pinhão/ Guarapuava. In: ENCONTRO INTERNACIONAL DE PRODUÇÃO CIENTÍFICA, 11., 2019, Maringá. Anais... Maringá, UNICESUMAR, v. 1, p. 1-10.

Bigham, J.M., Fitzpatrick, R.W. \& Schulze, D.G. 2002. Iron Oxides. In: Dixon, J.B. \& Schulze, D.G. (Ed.). Soil Mineralogy with Environmental Applications. Madison, Wisconsin: Soil Science Society of America, p. 323-366.

Bühmann, C. \& Grubb, P.L.C.A. 1991.KaolinSmectite Interstratification Sequence from a Red and Black Complex. Clay Minererals, 26(3): 343-358.

Calegari, M.R., Lopes-Paisani, S.D., Cecchet, F.A., Ewald, P.L.D.L., Osterrieth, M.L., Paisani, J.C. \& Pontelli, M. E. 2017. Phytolith signature on the Araucarias Plateau - Vegetation change evidence in Late Quaternary (South Brasil). Quaternary International, 434(B): 117-128.

Catt, J.A. 1990. Paleopedology manual. Quaternary International, 6: 2-95.

Clemente, C.A. \& Azevedo, A.C.D. 2007. Mineral weathering in acid saprolites from subtropical, Southern Brazil. Scientia Agricola, 64(6): $601-$ 607.

Costa, A.C.S. \& Bigham, J.M. 2009. Óxidos de ferro. In: Melo, V.F. \& Alleoni, L.R.F. (Ed.). Química e mineralogia do solo: parte 1 - Conceitos básicos. Viçosa, Sociedade Brasileira de Ciências do Solo, p. 505- 572.

Delvigne, J.E. 1998. Weathering and Alterites. In: Delvigne, J.E. (Ed.). Atlas of micromorphology of mineral alteration and weathering. Canadá: mineralogical association of Canada and Orstom Editions, p. 7-31.

Douglas, L.A. 1989. Vermiculites. In: Dixon, J.B. \& Weed, S.B. (Ed.). Minerals in soil environments. $2^{\text {nd }}$ ed. Madison, Wisconsin: Soil Science Society of America, p. 635-674.

Duchaufour, P. 1997. Abrégé de Pédologie: sol, végétation, environnement. Paris, Masson, $291 p$.

Fodor, R.V., Mckee, E.H. \& Roisenberg, A. 1989. Age distribution of Serra Geral (Paraná) flood basalts, southern Brazil. Journal of South American Earth Sciences, 2(4): 343-349.

Gaspari, M.C. 2017. Grau de evolução pedogeoquímica da superfície geomorfológica de Xanxerê (SC) - Planalto das Araucárias. Francisco Beltrão, 111p. Dissertação de Mestrado, Programa de Pós-Graduação em Geografia, Universidade Estadual do Oeste do Paraná

Gaspari, M.C., Pontelli, M.E \& Biffi, V.H.R. 2020. Natureza poligenética de latossolo bruno em patamares extensos no Meio-Oeste catarinense - Planalto das Araucárias. Geografia Ensino \& Pesquisa 24:23.

Grimm, E.C., Lozano-García, S., Behling, H. \& Markgraf, V. 2001. Holocene Vegetation and Climate Variability in the Americas. In: Markgraf, V. (Ed.). Interhemispheric Climate Linkages. Cambridge, Academic Press, p. 325-370.

Gu, F., Zonneveld, K.A.F., Chiessi, C.M., Arz, H.W., Pätzold, J. \& Behling, H. 2017. Long-term vegetation, climate and ocean dynamics inferred from a 73,500 years old marine sediment core (GeoB2107-3) off southern Brazil. Quaternary Science Review, 172(15): 55-71.

Guerra, S. \& Paisani, J.C. 2014. Mineralogia da fração argila do registro estratigráfico do Planalto De Água Doce/Palmas (Sul do Brasil): Primeira aproximação. RA'EGA, 31: 208-226.

Hsu, P.H. 1989. Aluminiun oxides and oxyhydroxides. In: Dixon, J.B. \& Weed, S.B. (Ed.). Minerals in soil environments. Madison, Wisconsin: Soil Science Society of America, p. 331-378.

Hughes, P.D. 2010. Geomorphology and Quaternary stratigraphy: role of morpho-, litho-, and alloestratigraphy. Geomorphology, 23(3-4): 189-199.

Kämpf, N. \& Curi, N. 2000. Óxidos de ferro: indicadores de ambientes pedogênicos e geoquímicos. In: Novais, R.F., Alvarez, V.H. \& Schaefer, C.E.G.R. (Ed.). Tópicos em ciência do solo - Volume1. Viçosa, Sociedade Brasileira 
de Ciência do Solo, p. 107-138.

Kämpf, N., Curi, N. \& Marques, J.J. 2009. Intemperismo e ocorrência de minerais no ambiente do solo. In: Melo, V.D.F. \& Alleoni, L.R.F (Ed.). Química e mineralogia do solo: parte I - Conceitos básicos. Viçosa, Sociedade Brasileira de Ciências do Solo, p. 333- 379.

Lopes-Paisani, S.D., Paisani, J.C., Osterrieth, M.L. \& Pontelli, M.E. 2016. Significado paleoambiental de fitólitos em registro pedoestratigráfico de paleocabeceira de drenagem - Superfície de Palmas/Água Doce (Sul do Brasil). Geociências, 35(3):426-442.

Malla, P. B. 2002. Vermiculites. In: Dixon, J. B. \& Schulze, D. G. (Ed.). Soil Mineralogy with Environmental Applications. Texas, A\&M University, p. 501-529.

Mateus, A.C.C., Oliveira, F.S.D., Varajão, A.F.D.C. \& Soares, C.C.V. 2017. Genesis of soils from bauxite in Southeastern Brazil: Resilication as a soil-forming process. Revista Brasileira de Ciências do Solo, 41: 1-18.

Melfi, A.J. \& Pedro, G. 1977. Estudo geoquímico dos solos e formações superficiais do Brasil: Parte 1 - caracterização e repartição dos principais tipos de evolução pedogeoquímica. Revista Brasileira de Geociências, 7(4): 271286.

Melo, V.D.F. \& Wypych, F. 2009. Caulinita e Haloisita. In: Melo, V.D.F. \&Alleoni, L.R.F (Ed.). Química e mineralogia do solo: parte 1 Conceitos básicos, v. 6, Viçosa, Sociedade Brasileira de Ciências do Solo, p. 427- 504.

Menegotto, E. \& Gasparetto, N.V.L. 1987. Intemperização de rochas vulcânicas básicas e cidas na região de Santa Maria, RS. In: CONGRESSO BRASILEIRO DE GEOQUÍMICA, 1, 1987, Santa Maria. Anais... Santa Maria, Sociedade Brasileira de Geoquímica, 1987. v.2. p. 69-83.

Mineropar. MINERAIS DO PARANÁ S.A. 2013. O Grupo Serra Geral no Estado do Paraná Mapeamento Geológico das cartas 1:250.000 de Guaíra, Cascavel, Campo Mourão, Foz do Iguaçu, Guaraniaçu, Guarapuava, Pato Branco e Clevelândia. volume 1 - Texto. Curitiba, MIEROPAR, 2013, 456 p.

Moore, D.M. \& Reynolds Jr, R.C. 1997. X-Ray Diffraction and the Identification and Analysis of Clay Minerals. New York, Oxford University Press, 378p.

Morrás, H., Moretti, L., Piccolo, G. \& Zech, W. 2009. Genesis of subtropical soils with stony horizons in NE Argentina: Autochthony and polygenesis. Quaternary International, 196: $1-2$.

Nardy, A.J.R., Oliveira, M.A.F., Betancourt, R.H.S., Verdugo, D.R.H. \& Machado, F.B. 2002. Geologia e estratigrafia da Formação Serra Geral. Geociências, 21(1-2): 15-32.

Ojanuga, A.G. 1979. Clay Mineralogy of Soils in the Nigerian Tropical Savanna Regions. Soil Science Society of America Journal, 43(6): 1237-1242.

Paisani, J.C., Pontelli, M.E. \& Andres, J. 2008. Superfícies aplainadas em zona morfoclimática subtropical úmida no planalto basáltico da Bacia do Paraná (SW Paraná/ NW Santa Catarina): primeira aproximação. Geociências, 27(4): 541-553.

Paisani, J.C., Pontelli, M., Corrêa, A.C.D.B. \& Rodrigues, R.A.R. 2013a. Pedogeochemistry and micromorphology of oxisols - A basis for understanding etchplanation in the Araucárias Plateau (Southern Brazil) in the Late Quaternary. Journal of South American Earth Sciences, 48: 1-12.

Paisani, J.C., Calegari, M.R., Pontelli, M.E., Pessenda, L.C.R., Côrrea, A.C.D.B., LopesPaisani, S.D. \& Raitz, E. 2013b. O papel das mudanças climáticas do Quaternário Superior na dinâmica evolutiva de paleovale de segunda ordem (Sul do Brasil). Revista Brasileira de Geomorfologia, 14(1): 103-116.

Paisani, J.C., Pontelli, M.E., Osterrieth, M.L., Paisani, S.D.L., Fachin,A., Guerra, S. \& Oliveira, L. 2014. Paleosols in low-order streams and valley heads in the Araucaria Plateau - Record of continental environmental conditions in Southern Brazil at the end of MIS 3. Journal of South American Earth Sciences, 54: 57-70.

Paisani, J.C., Pontelli, M.E. \& Calegari, M.R. 2015. Contribuição para a reconstrução de paleoperfis de alteração no Planalto de Palmas/Água Doce - Sul do Brasil. GEOgraphia, 17(34): 225-246.

Paisani, J.C., Fachin, A., Pontelli, M.E., Osterrieth, M.L., Lopes-Paisani, S.D. \& Fujita, R.H. 2016. 
Evolução de paleocabeceira de drenagem do rio Chopinzinho (sul do Brasil) durante o Quaternário Superior. Revista Brasileira de Geomorfologia, 17(1): 43-59.

Paisani, J.C., Lopes-Paisani, S.D., Osterrieth, M.L., Pontelli, M.E. \& Fujita, R.H. 2017. Dinâmica de rampa de colúvio na Superfície de Palmas/ Água Doce durante o Quaternário Tardio bases para compreender a evolução das encostas no Planalto das Araucárias. Revista Brasileira de Geomorfologia, 18(4): 783-799.

Paisani, J.C., Lopes-Paisani, S.D., Lima, S., Ribeiro, F.D.J., Pontelli, M.E. \& Fujita, R.H. 2019. Paleoenvironmental dynamics of low-order paleovalleys in the Late Quaternary - Palmas/ Caçador Summit Surface - Southern Brazil. Catena, 182: e104171.

Pontelli, M.E. \& Paisani, J.C. 2015. Foz do Iguaçú: Geomorphological Context of the Iguaçú Falls. In: Vieira, B.C., Salgado, A.A.R. \& Santos, L.J.C. (Ed.). Landscapes and Landforms of Brazil. New York, Springer International Publishing, p. 339-347.

Rebertus, S., Weed, S. \& Buol, S. 1986. Transformations of biotite to Kalinite during saprolite-soil weathering. Soil Science Society of American Journal, 50: 810-819.

Resende, M., Curi,N., Ker, J.C. \& Rezende, S.B. 2005. Mineralogia de solos brasileiros: interpretações e aplicações. Lavras, Editora UFLA, 192p.

Rich, C.I. 1956. Muscovite weathering in a soil developed in the Virginia Piedmont. Clays and Clay Mineralogy, 5(1): 203-212.

Riffel, S.B., Vasconcelos, P.M., Carmo, I.O. \& Farley, K.A. 2016. Goethite (U-Th)/He geochronology and precipitation mechanisms during weathering of basalts. Chemical Geology, 446: 18-32.

Ross, G.J., Wang, C., Ozkan, A.I. \& Rees, H.W. 1982. Weathering of chlorite and mica in a new Brunswick Podzol developed on till derived from chlorite-mica schist. Geoderma, 27(3): 255-267.

Ryan, P. C. \& Huertas, F. J. 2009. The temporal evolution of pedogenic Fe-smectite to $\mathrm{Fe}$ kaolin via interstratified kaolin-smectite in a moist tropical soil chronosequence. Geoderma, 151(1-2): 1-15.
Santos, L.J.C., Oka-Fiori, C., Canali, N.E., Fiori, A. P., Silveira, C.T., Brisk, S. J. \& Silva, J.M.F. 2006. Atlas Geomorfológica do Estado do Paraná. Curitiba/PR, Imprensa oficial, 59p.

Schenato, F., Formoso, M.L.L., Meunier, A., Proust, D. \& Mas, A. 2003.Alteration processes of a thick basaltic lava flow of the Paraná Basin (Brazil): petrographic and mineralogical studies. Journal of South American Earth Sciences, 16(5): 423-444.

Schwertmann, U. \& Taylor, R.M. 1989. Iron Oxides. In: Dixon, O.J.B. \& Weed, S.B. (Ed.). Minerals in soil environments. Madison, Wisconsin, $\mathrm{p}$. 379-438.

Smith, W.W. 1962. Weathering of Some Scottish Basic Igneous Rocks With Reference To Soil Formation. Journal of Soil Science, 13: 202215.

Targulian, V.O. \& Goryachkin, S. 2004. Soil memory: Types of record, carries, hierarchy and diversity. Revista Mexicana de Ciências Geológicas, 21(1): 1-8.

Teske, R., Almeida, J.A., Hoffer, A., \& Neto, A.L. 2013. Caracterização mineralogical dos solos derivados de rochas efusivas no Planalto Sul de Santa Catarina, Brasil. Revista de Ciências Agroveterinárias, 12(2): 187-198.

Thomas, M.F. 1989. The role of etch processes in landform development II. Etching and the formation of relief. Zeitschrift für Geomorphologie, 33(3): 257-274.

Thomas, M.F. 2003. Late Quaternary sediments fluxes from tropical watersheds. Sedimentary Geology, 162(1-2): 63-81.

Thomas, M.F. 2008. Understanding the impacts of Late Quaternary climate change in tropical and sub-tropical regions. Geomorphology, 101(1-2): 146-158.

Vicente-Hernandez, J., Vicente, M.A., Robert, M. \& Goodman, B.A. 1983. Evolution des biotites en fonction des conditions d'oxydo-reduction du milieu. Clay Minerals, 18(3): 267-275.

Vingiani, S., Righi, O., Petit, S. \& Terribile. F. 2004. Mixed-layer kaolinite-smectite minerals in a red-black soil sequence from basalt in Sardinia (Italy). Clays and Clay minerals, 52(4): 473-483.

Volkmer, S. 1999. Mineralogia e morfologia de coberturas de alteração desenvolvidas em 
rochas vulcânicas ácida: os exemplos de Palmas e Pinhão, PR. São Paulo, 184p. Tese Doutorado, Programa de Pós Graduação em Geoquímica e Geotectônica, Instituto de Geociências, Universidade de São Paulo.

Young, A. \& Stephen, I. 1965. Rock weathering and soil formation on high altitude plateaux of Malawi. Journal of Soil Science, 16(2): 322333. 